OPEN ACCESS

Communication-Micro-Scale Columnar Architecture Composed of Copper Nano Sheets by Electrodeposition Technique

To cite this article: Susumu Arai et al 2017 J. Electrochem. Soc. 164 D72

View the article online for updates and enhancements. 


\title{
Communication-Micro-Scale Columnar Architecture Composed of Copper Nano Sheets by Electrodeposition Technique
}

\author{
Susumu Arai, ${ }^{*, z}$ Masaya Ozawa, and Masahiro Shimizu* \\ Departments of Materials Chemistry, Faculty of Engineering, Shinshu University, Nagano-shi, Nagano 380-8553, \\ Japan
}

\begin{abstract}
Micro-scale columnar architectures composed of copper sheets with nanometer thickness were fabricated by electrodeposition using a photolithography technique. A copper sulfate solution containing a polyacrylic acid was used as the plating bath, and the electrodeposition was conducted under galvanostatic conditions. Patterned electrodeposits with a cylindrical shape and composed of thin copper sheets were formed. Every copper deposit had openings on the top and side regions and also had a porous interior. This novel three-dimensional (3D) copper architecture should provide functional copper electrodes with large effective surface areas.

(C) The Author(s) 2016. Published by ECS. This is an open access article distributed under the terms of the Creative Commons Attribution 4.0 License (CC BY, http://creativecommons.org/licenses/by/4.0/), which permits unrestricted reuse of the work in any medium, provided the original work is properly cited. [DOI: 10.1149/2.1101702jes] All rights reserved.

(cc) BY
\end{abstract}

Manuscript submitted November 1, 2016; revised manuscript received December 12, 2016. Published December 30, 2016.

Since three-dimensional (3D) nanostructured metal architectures have large surface areas as well as high electrical conductivities, their application as electrodes for devices such as supercapacitors, ${ }^{1}$ fuel cells, ${ }^{2}$ and batteries ${ }^{3}$ has been intensively researched. In particular, the application of 3D copper nanostructured architectures in components such as tin-based lithium-ion battery anodes ${ }^{4-8}$ and glucose sensors $^{9-11}$ is currently one of the hottest areas of research. Various methods of forming 3D copper architectures have been examined, including de-alloying of copper from an $\mathrm{Al}-\mathrm{Cu}$ alloy ${ }^{4}$ and electrodeposition of copper using templates such as hydrogen bubbles ${ }^{5-7}$ or porous alumina. ${ }^{8}$ Our group has developed a very simple templatefree method for fabricating 3D copper nanostructured architectures by one-step electrodeposition in which an organic additive is introduced to the electrodeposition bath. ${ }^{12}$ The $3 \mathrm{D}$ copper architecture formed by the one-step electrodeposition (3DC1) consists of thin copper sheets and has a porous interior. Although such 3D architectures have large surface areas and can therefore be expected to be useful as highreaction-rate electrodes, the bottom region of the structures is often not fully functional due to an insufficient supply of electrochemically active species. If the electrode reaction rate is dominated by such transport limitations, then improvement in the supply rate of the active species toward the outer Helmholtz plane of the deep interior electrode surface should increase the reaction rate. In general, pattern plating using thick photoresists can provide fine metal structures with a high aspect ratio. If the patterned structures have a columnar shape, they can make contact with the surrounding media, such as the electrolyte, not only at the top surface but also at the side surface, improving the supply rate of active species to the deep interior surface. Therefore, patterned columnar 3DC1 is expected to exhibit high reaction rates.

In this study, patterned 3DC1 was formed by electrodeposition using a photolithography technique, and the microstructure of the electrodeposits was analyzed.

\section{Experimental}

A sulfuric plating solution composed of $0.85 \mathrm{M} \mathrm{CuSO}_{4} \cdot 5 \mathrm{H}_{2} \mathrm{O}$ and $0.55 \mathrm{M} \mathrm{H}_{2} \mathrm{SO}_{4}$ was used as the base plating bath. $3 \times 10^{-4} \mathrm{M}$ polyacrylic acid (mean molecular weight 5000: PA-5000) was added to the base plating bath, resulting in the 3DC1 plating bath. The process of fabricating a patterned 3DC1 is summarized in Fig. 1. A pure copper substrate was coated with a negative-type dry film photoresist (RY-3025, Hitachi Chemical Co., Ltd.) approximately $30 \mu \mathrm{m}$ thick, and then patterned using a photomask with an arrangement of $50-\mu \mathrm{m}$-diameter circles at $50 \mu \mathrm{m}$ intervals. A copper plate containing phosphorous was used as the anode. The electrodeposition of copper

*Electrochemical Society Member

${ }^{\text {z} E-m a i l: ~ a r a i s u n @ s h i n s h u-u . a c . j p ~}$ onto the substrate (the exposed copper surface area, i.e., the total surface area of the circles, was approximately $2 \mathrm{~cm}^{2}$ ) was carried out under galvanostatic conditions $(20 \mathrm{~mA})$ using the $3 \mathrm{DC} 1$ plating bath without agitation at $25^{\circ} \mathrm{C}$. After the electrodeposition, the photoresist was removed using an alkaline solution, resulting in a patterned 3DC1. The morphology of the patterned 3DC1 was observed using field emission scanning electron microscopy (FE-SEM; SU8000, Hitachi High Technologies). Cross-sectional samples of the patterned $3 \mathrm{DC} 1$ were prepared using a focused ion beam system (JIB-4610F, JEOL) and observed by FE-SEM.

\section{Results and Discussion}

Exfoliation of the patterned photoresist from the copper substrate was not observed during any of the electrodeposition tests, and copper was perfectly deposited in the photoresist pattern in every electrodeposition test. Figure 2 shows SEM images of electrodeposits from the 3DC1 plating bath with $60 \mathrm{C}\left(30 \mathrm{C} \mathrm{cm}^{-2}\right)$ of charge transferred. The deposits were regularly spaced on the substrate, and all of the deposits had almost the same volume (Fig. 2a). Each electrodeposit had a similar cylindrical appearance and was composed of thin copper sheets. Furthermore, openings into the interior of the deposits were observed not only on the top surface, but also on the side surface (Fig. 2b).

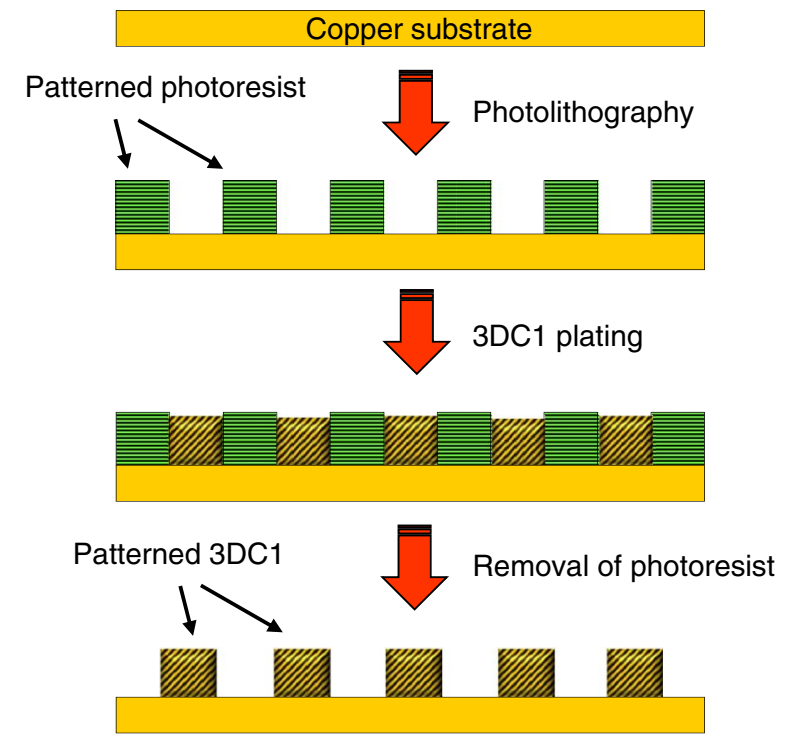

Figure 1. Schematic illustration of the fabrication process for the micro-scale columnar architecture composed of copper thin sheets. 


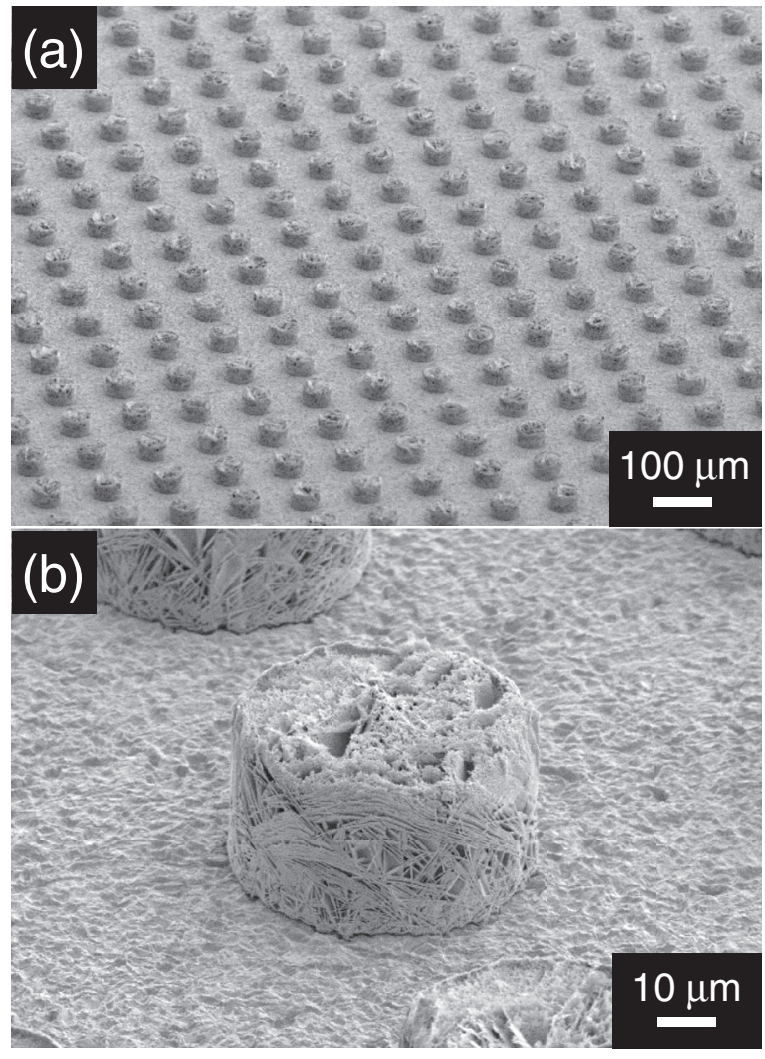

Figure 2. SEM images of patterned 3DC1: (a) low magnification and (b) high magnification. The amount of charge transferred is $60 \mathrm{C}\left(30 \mathrm{C} \mathrm{cm}^{-2}\right)$. The observation angle is $60^{\circ}$.

Figure 3 displays SEM images of the external appearance and cross sections of electrodeposits formed using various amounts of charge transferred. Each patterned electrodeposit grew while maintaining openings not only on the top surface but also on the side surface (Figs. 3a-3c). The deposited copper sheets tended to pile up when the amount of charge transferred increased (Fig. 3c). The crosssectional SEM images (Figs. 3a'-3c') show that these electrodeposits had pockets of open space even deep within them. Furthermore, the growth of the copper sheets terminated at the sides of the deposits. This means that the copper sheets stop growing when they meet the inner surface of the patterned photoresist. The thickness of the patterned electrodeposits was measured from the cross-sectional SEM images, taking the observation angle into account. Furthermore, the porosity of the deposits was estimated from the measured thickness of the deposits and the calculated thickness of a dense copper deposit using Faraday's law of electrolysis.

Figure 4 shows the relationship between the amount of charge transferred, the thickness of the deposits, and the porosity of the deposits. The thickness of the deposits increased monotonically with increasing amount of charge transferred, but not in a linear fashion. Although the porosity was approximately $70 \%$ regardless of the amount of charge transferred, it tended to decrease with increasing energizing quantity. As shown in Figs. $3 \mathrm{c}$ and $3 \mathrm{c}^{\prime}$, the copper sheets tended to pile up as the amount of charge transferred was increased. This would be expected to decrease the porosity of thicker patterned deposits. The suppression of such pile-up should be an effective means of maintaining high porosity even for thicker deposits, and this will be addressed in future work.

\section{Summary}

Patterned 3DC1 was fabricated using an electrodeposition technique assisted by photolithography. Cylindrical copper electrodeposits

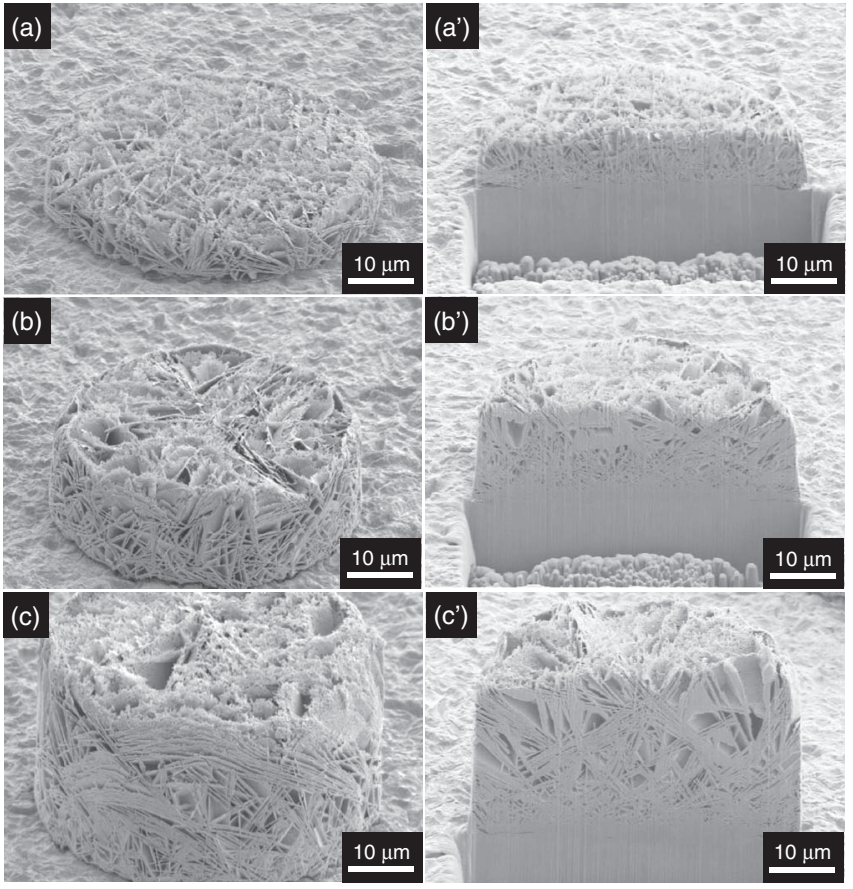

Figure 3. SEM images of patterned deposits formed under various amounts of charge transferred: (a) exterior and (a') cross section at $15 \mathrm{C}$, (b) exterior and (b') cross section at $30 \mathrm{C}$, and (c) exterior and (c') cross section at $60 \mathrm{C}$. The observation angle is $60^{\circ}$.

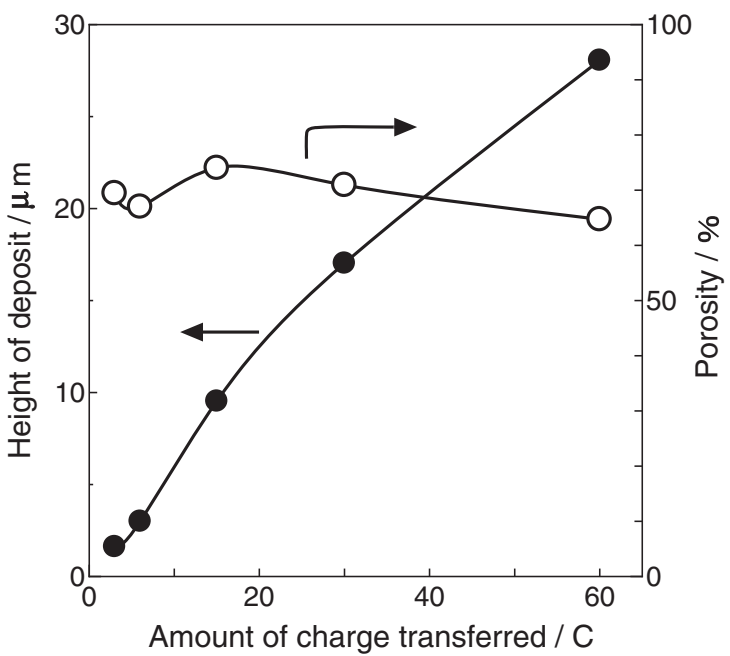

Figure 4. Relationship between amount of charge transferred, thickness of deposit, and porosity.

composed of thin copper sheets with porous interiors were formed. The deposits contained openings not only at the top but also on the sides. Patterned 3DC1 can be applied to high-performance functional electrodes.

\section{Acknowledgment}

This work was supported by JSPS KAKENHI grant Number JP26289270.

\section{References}

1. S. Ghosh and O. Inganas, Adv. Mater., 11, 1214 (1999).

2. Y. Liu, S. Zha, and M. Liu, Adv. Mater., 16, 256 (2004)

3. D. R. Rolison and B. Dunn, J. Mater. Chem., 11, 963 (2001). 
4. S. Zhang, Y. Xing, T. Jiang, Z. Du, F. Li, L. He, and W. Liu, J. Power Sources, 196 6915 (2011).

5. H. C. Shin, J. Dong, and M. Liu, Adv. Mater., 15, 1610 (2003).

6. H. C. Shin and M. Liu, Chem. Mater, 16, 5460 (2004).

7. T. Jiang, S. Zhang, X. Qiu, W. Zhu, and L. Chen, J. Power Sources, 166, 503 (2007)

8. J. Hassoun, S. Panero, P. Simon, P. L. Taberna, and B. Scrosati, Adv. Mater., 19, 1632 (2007).
9. X. Niu, Y. Li, J. Tang, Y. Hu, H. Zhao, and M. Lan, Biosensor and Bioelectronics, 51, 22 (2014).

10. Y. Hu, X. Niu, H. Zhao, J. Tang, and M. Lan, Electrochim. Acta, 165, 383 (2015).

11. X. Li, B. Huang, C. Qiu, Z. Li, L. H. Shao, and H. Liu, J. Alloys Compd., 681, 109 (2016).

12. S. Arai and T. Kitamura, ECS Electrochem. Lett., 3, D7 (2014) 